\title{
Using Mind-Set Information About Health, Pleasure and Function to Understand Consumer Choices in Bottled Water
}

\author{
Andrea Maier ${ }^{1}$, Howard R. Moskowitz ${ }^{* 2}$, Jacqueline Beckley ${ }^{3}$ and Hollis Ashman ${ }^{3}$ \\ ${ }^{1}$ FCI - Food Consumer Interaction Department, Nestlé Research Center, PO Box.44, CH-1000 Lausanne 26, \\ Switzerland \\ ${ }^{2}$ Moskowitz Jacobs Inc., 1025 Westchester Ave., $4^{\text {th }} \mathrm{fl}$, White Plains, NY, 10604, USA \\ ${ }^{3}$ The Insight and Understanding Group, Denville, New Jersey, USA
}

\begin{abstract}
Purpose: The objective of this paper is to demonstrate that databases of consumer mind-sets, created by experimental design, can be combined and analyzed to identify new product opportunities for foods and beverages.

Methodology/Approach: This paper analyzes responses to test concepts about bottled water from five different mind-set databases (Crave It! 2001 for adults, teens; Drink It! 2002 and 2004; Healthy You! 2003), each focusing on a different aspect of food/drink, but each containing a study about bottled water. The databases combine conjoint analysis with extensive classification, which generate parallax views about bottled water from different vantage points

Practical Implications: Based upon strong performance of specific elements across databases for different end-uses, the analyses suggest that a market exists for bottled water containing strong health benefits, as well as a strong opportunity for functional bottled water specifically targeting younger consumers.
\end{abstract}

Originality: The paper presents a unique new approach to understanding the mind-set of consumers by combining information from concept databases.

Keywords: Concept database, consumer, conjoint analysis, segmentation, water.

\section{INTRODUCTION TO THE BUSINESS PROBLEM: THE IMPORTANCE OF BOTTLED WATER, BUT OF WHAT TYPE?}

New product development in the beverage industry often comes from line extensions or from the availability and introduction of new technology. There are dozens of brands and many different kinds of bottled water, including flavored or fizzy, creating a dizzying array from which to choose. Bottled water, positioned as quenching the thirst, represents one of the fastest-growing private label categories. With sales approaching $\$ 8$ billon, bottled water is one of the mostconsumed beverages in America. Sales are projected to go beyond carbonated soft drinks by the end of the decade [1]. Interestingly, single-serve bottled water is purchased most frequently, similar to conventional single-serve soft drinks. The increased use of bottled water may result from substitution behavior, namely the consumer shift away from soft drinks and other beverages.

Water belongs to a category one might loosely call 'functional beverages,' which represent one of the industry's most innovative and trend-sensitive categories. They increase in sales every year. The trend for the growth of functional beverages was apparent as far back as eight years ago, when they were projected to reach around $\$ 16$ billion by 2010 and to be among the strongest, if not the strongest performers in

*Address correspondence to this author at the Moskowitz Jacobs Inc., 1025 Westchester Ave., $4^{\text {th }}$ fl, White Plains, NY, 10604, USA; Tel: 914-4217400; Fax: 914-428-8364; E-mail: mjihrm@sprynet.com the beverage industry [2]. These functional beverages are classified as having some manner of enrichment attached to them. Almost every type of drink from water to juice has undergone some enrichment in order to take advantage of consumer requirements for this emerging market. Functional beverages include calcium-fortified orange juice, herbal iced teas, sports drinks, soymilk, medicinal teas, powdered drink mixes, cranberry and prune juices in their study. However, the attachment of water to these enriched functional beverages is a bit ambiguous, because quite often marketers of bottled water proudly proclaim the product pure and natural, free of any additives.

A complex mix of consumer preferences, changing demographics and socio-economic factors is boosting the market demand for healthy water products. Health is an important factor influencing beverage sales, with the benefits of drinking water well publicized in recent years. An increasing number of people are making it a habit to stay well-hydrated during the day, making bottled water a constant companion and, in some cases, a fashion accessory. The desire for good health and the concern over bottle water consumption has driven consumers to drink more water beverages. Trends for health oriented water include natural fortification, organic sodas, purity, or new and exotic flavors such as lemon dew, key lime, etc. Factors that are undesirable for a healthoriented water based beverage are: artificial colorings, artificial sweeteners and caffeine. Consumers definitely do not want these ingredients in their healthy beverages, forcing companies to figure out what specific functional ingredients are compelling and which are to be avoided. For example, 
Nestle introduced Aquarel natural-spring, low-calorie water with ginseng and herbal essences to "refresh and revitalize" to the mass market in Europe.

\section{Demographics and Market Factors Driving Interest in Bottled Water}

Long consumed by health-conscious adults, bottled water has found a broader audience among America's youth and women, with younger, health-oriented people driving the market's growth. At the time of this writing (2008), flavored waters definitely appear to have the most consumer interest. Previous research showed that younger people seek new flavors more frequently than do older people [3]. Consumers are searching for better tasting, less bland beverages that will also quench their thirst. These products are capturing the younger generation as well as the health-conscious adults. As consumers become even more health-conscious and informed, the enhanced water product category will become even more important; other needs will emerge to be satisfied. There is a growing market for bottled water specially formulated for women and youngsters, which features added calcium, potassium, and zinc, etc.

\section{Water as a Sport Drink}

The sports water segment includes bottled waters that contain additions such as vitamins and flavors. So-called sports nutritionals have gained wide acceptance as an essential component of a committed athletic lifestyle. Increasing numbers of consumers, who aren't necessarily health club devotees, are also turning to sports nutritionals, often in lieu of traditional water beverages. These waters contain added vitamins that the body needs and are marketed to the active population seeking extra enhancement from their water to aid workouts. Gatorade's Propel ${ }^{\circledR}$ fits into this category. Propel ${ }^{\circledR}$ contains three B vitamins claimed to facilitate metabolism at the cellular level. Form is also following function. Squeeze sport bottles are available for people "on the go" who do not want to drink water from public fountains.

\section{INTRODUCTION TO CONSUMER KNOWLEDGE: SENSORY ANALYSIS AND DATABASES OF THE CONSUMER MIND}

In connection with human eating habits, an array of studies, some more extensive and some superficial, have been carried out for nearly all kinds of beverages. With respect to drinking habits, however, almost no data are available concerning individuals' consumption of drinking water, although drinking water is one of the most important kinds of foods $[4,5]$. Most of the consumer research in water assessment and its properties are limited to survey data collection in which participants give ratings about water quality factors. Some studies suggest that taste, in actuality, is the primary reason cited when deciding whether to buy a particular beverage [6].

Sensory assessment is the only means by which the consumer can directly evaluate water quality and safety. With increasing public and regulator pressure to provide water that is free from off-flavors, the water industry has recognized the importance of information about the sensory origins of customer satisfaction with the taste and odors of drinking water. Yet little is known about the positive aspects of taste and odor of drinking water as a driver of acceptance. We are all familiar with the negatives of bad taste and odor, but the positive aspects present a new opportunity for knowledge in an important product category. There is an interest in identifying and evaluation undesirable tastes in drinking water by sensory test procedures [7], which is important given the additives in bottled water.

The analyses presented here show how new consumer research methods in concept assessment can be applied to the generation of knowledge databases for the bottled water industry. The development process involves testing systematically varied concepts with consumers with the goal of creating a consumer-based 'concept model' showing how the different statements about concepts drive acceptance of bottled water. Positioning these models in the context of three different reference frames ("for your health', "intensity of craving", "interest in drinking") allows the researcher to understand water from several different perspectives commonly adopted by a consumer, albeit at the cognitive descriptive level prior to tasting, rather than at the sensory level after tasting.

The conjoint analysis research method has already been used to understand the interplay of different factors for a variety of foods and beverages [8]. The focus on one beverage from different frames of reference is, however, a new contribution to both consumer understanding and the water industry, respectively. More specifically, understanding how three different mindsets ("for your health", "intensity of craving", "interest in drinking") drive responses to product concepts reveals how consumer acceptance and purchasing behavior are driven by mind-sets.

Such knowledge can also allow producers to more effectively and efficiently develop new drinks that appeal to consumers. For example, the large number of choices available on any store shelf that contains bottled water require that marketer produce the right vision of sparkling and pure water in the consumers' mind whenever the consumers look at the package. The most effective type of packaging material, its color, and later on, the label design are some of the areas the water industry has to consider as well. When designing the package, the main consideration is convenience for carrying and drinking while on the run. Knowledge of this type identifies the key consumer drivers for purchase, whether sensory experience or package experience, or even emotional connection. These elements should be incorporated into the product concept in order to reveal how sensory attributes trade-off against emotion, convenience, and brand characteristics for bottled water.

\section{Steps to Better Consumer Understanding: The Role of Idea Archives}

Marketers have long recognized the value of a good idea, although there is no consensus about how to create such an idea, whether in bottled water or in other categories. Some marketing research practitioners believe that the key ingredient is 'creativity', often ill defined, but embodied in a commercial process. For example, one might select so-called 'lead users', who are defined as those individuals who try a product before anyone else [9]. Another approach works with so-called 'creative consumers', defined as articulate individuals who score highly on a standardized test that is assumed to measure creativity. A third approach uses brain- 
storming techniques in a focus group, so one person may come up with a thought, present it to the group, allowing another person to modify it, enhance it, or turn the idea into an entirely different direction. In the main, companies use variations of these approaches, such as ethnography [10], to get closer to the consumer mind, in the effort to create this product idea.

Corporate archives are filled with the results of concept studies for new products, some acceptable and some failures, either at the early design stage or later in the market. One of the recurrent problems in concept research is the failure of companies to create a searchable system with which to archive ideas, products, executions, and marketing plans that are good or bad. Indeed, very rarely are "post mortems" conducted to truly understand what part of a poor project execution is related to the product and what part is related to the idea or concept as executed. A consequence of this is the lack of a database for marketers and developers to identify how well ideas, in combination with product attributes perform, beyond the limited attention paid to the particular project.

Having an archive for concept ideas will come to naught if there is no powerful method to fill that archive with meaningful concept information. One of the most popular methods for concept design, which helps reveal the features that consumers find important is the class of procedures known as conjoint analysis [8]; which combines features of products into test concepts. These test concepts are systematically varied. That means that the respondent may evaluate a concept that comprises different messages, one message being brand name, another being source of the product, a third and perhaps a fourth being product features. The reactions of respondents to these systematically varied combinations allow the researcher to estimate the part-worth contribution or 'utility' of each element. Even though the elements appear as independent agents in the concepts, the experimental design permits the researcher to disentangle these part-worth contributions, using a well defined procedure such as overall linear regression [11].

Traditionally, researchers have used conjoint analysis in a 'one-off' mode, concentrating on a specific problem of momentary import and focusing on a single product. A potentially more productive approach follows this archive idea, embedding the conjoint study for one product in a set of parallel conjoint studies for similar products (e.g., embedding the study for water in a larger-scale set of studies for beverages). In this way, the product developer and marketer discover how the concept elements for the particular product perform versus the concept elements for the full set of similar products. Beckley \& Moskowitz [12] and Moskowitz., German \& Saguy [13] presented details of this database approach using a set of related conjoint studies called the It! Databases. We will explore the results of this early thinking by means of the same type of product (water) evaluated in the context of three separate databases, each driven by a specific consumer mind-set.

\section{Steps to Better Consumer Understanding: The Role of Concept-Response Segmentation}

Marketers have long known that responses to products and concepts do not follow easy-to-measure attributes such as gender, age, market, or even co-vary with purchase behavior such as brand of water used most often. That is, a researcher can differentiate people on the basis of many different types of measures, but often these easy-to-define subgroups of individuals appear to be very similar in the pattern of their responses to concept stimuli. We might expect this type of similarity to emerge for water as well, and can test that empirically.

A more profitable way to divide respondents based on conjoint analysis looks at their patterns of utilities, which shows the types of elements in concepts that drive their acceptance. Individuals with similar utility patterns fall into the same segment because these individuals react to the same types of concept elements. Individuals with different patterns of reactions should fall into different segments. This is known by the general phrase latent class segmentation, because the clustering divides people based upon latent or hidden factors, rather than dividing respondents by the more conventional variables such as age, income, brand usage, etc. Statistical methods abound for such latent class segmentation [14] and have been used profitably for more than two decades to divide respondents into these more meaningful subgroups. Meaningful here is used in the sense that the respondents in the same segment should show similar patterns of acceptance for a concept and, thus, can be marketed to in similar ways.

A key benefit of working across different databases with the same type of beverage, here water, is the possibility that one might discover similar latent class segments emerging from the different databases, or at least one might find a few segments that continue to emerge from database to database with other, more provincial, less general segments emerging in one database but not another. In a previous paper on coffee, Moskowitz [15] suggested that the same segments may exist world wide for a product, across different countries, albeit in different proportions. This organizing principle can be applied to the current database as well, but instead of different countries, we deal with different types of databases.

\section{Scope of this Paper}

This paper presents an analysis of data for water from three different types of databases. Each of the studies followed the same general structure, comprising 36 concept elements for water, with elements in each study ranging from product description to brand to emotional benefit to use, and to health benefit, respectively. The elements differed across the three databases, but shared a number of similarities that will become clearer in the detailed results.

\section{METHOD}

\section{General Overview of the Databases}

Each of the studies dealt with the response of several hundred respondents to systematically varied concepts created from small combinations of 36 elements each. The database in each study comprised utilities of the 36 concept elements estimated by regression analysis on a perrespondent basis, the average utility values from the total sample, and then average utilities from concept-response segments that emerged from clustering the utilities of individual respondents into groups with similar utility patterns. Rather than proceeding with a detailed methodological 
analysis of a single study we look at these three data sets to determine whether there are clear similarities that apply to water, that give us a sense of the mind of the consumer respondent.

The water was positioned in three different ways:

1. As a craved product (for adults and for teens, respectively, from the Crave It! database).

2. As a healthful beverage (from the Healthy You! database).

3. As a beverage (from the Drink It! database).

Each of the three databases mentioned above (Crave It!; Drink It!; Healthy You!) comprised 30 different but related conjoint studies, one study per product. The three databases each contained one study about bottled (and in some cases fresh) water, allowing the researcher to understand how consumer respondents evaluate concepts about 'water' in the context of other types of foods and beverages.

\section{The Components of the Database}

The individual conjoint studies in any particular database were constructed as follows:

1. Thirty different and relevant products were selected for the particular database. For Crave It! the products comprise different foods and beverages that might be 'craved' by consumers, with craving defined by the vernacular rather than by the medical use (i.e., the consumer might 'crave' a chocolate candy bar). For Healthy You! the foods and beverages were selected because of their healthful, nutritional properties. For Drink It! The set comprised all beverages that could be in the consideration set for drinking.

2. Each study for a particular food or beverage comprised 36 concept elements, divided into four silos. Table 1 shows an example of the silo and element structure for water assessed in the Crave It! database.

\section{EXPERIMENTAL DESIGN OF CONCEPT ELE- MENTS}

The concept research used conjoint analysis, a wellknown method in consumer research based upon experimental design of components, in which the components are mixed / matched in various combinations. The objective of experimental design is to understand the contribution of the components from responses to the mixture. Conjoint analysis has been a popular research tool in consumer marketing for approximately thirty years [16-18]. The ingoing belief of researchers using conjoint analysis is that respondents can more easily evaluate combinations that simulate small test advertisements than evaluate single ideas alone, especially when these ideas come from different silos such as product description, brand, and mood. Respondents more typically experience complex combinations, and evaluate these combinations in an intuitive way rather than logically proceeding from one idea to a different idea from an entirely different silo. Experimental design attempts to simulate the complexity of nature, although in a simplified, organized, and designed fashion.

Each conjoint analysis study for water comprised an experimental design with four silos and nine elements or vari- ables per category. Experimentally varied combinations or test concepts comprising either one or none of these four variables were developed by a computer program to ensure that the elements appeared equally often, and were statistically independent of each other. The statistical independence and missing silos, in some concepts, makes it straightforward to analyze the data by ordinary least-squares analysis, and database the coefficients or utility values.

Each easy-to-read test concept comprised 2-4 concept elements, with no more than one element from a silo appearing. By ensuring that one or two silos were absent in some concepts, the experimental design made it possible to run ordinary least squares regression, and estimate the absolute value of the coefficients, rather than the relative values. This approach of working with incomplete concepts that lack specific silos differs from the more conventional conjoint methods, which force every concept to contain one element from each category. By forcing the concepts to be 'complete' in this fashion the researcher ends up with an 'effects model' whose coefficients are relative within a silo, and cannot be compared across silos. The present approach avoids that problem entirely having true 'zero' conditions in the concept, where the category simply does not appear.

The basic experimental design comprised 60 combinations of these 36 elements, so that $r$ each respondent saw the same element three times across different backgrounds. Unlike conventional conjoint analysis methods (e.g., SPSS, Sawtooth) where the researcher creates a fixed set of concepts that is shown to all respondents, the IdeaMap®.Net method systematically permutes a basic design, so that every respondent evaluates a different design. The conventional approach to developing one specific set of 60 combinations (from a possible design space of $10^{4}-1=9999$ combinations) attempts to represent the full set of combinations, but only corresponds to $0.6 \%$. With this limited coverage, there is the possibility that some combinations may work very well together by accident, or suppress each other, by accident, thus biasing the results. The limited coverage of the design space by one set of combinations is always subject to this potential bias, which cannot be discovered, but which may be lurking. The permutation strategy maintains the basic design structure but ensures many more combinations, thus preventing a bias due to an unexpected superior or inferior performance of a few combinations [19]. A total of 400 such permuted designs were created for each study, ensuring a different permuted design per respondent. This strategy reduces the bias. When the respondent logged in for the study he was assigned to one of the permuted designs, which comprised the different concepts, further randomized to reduce order bias.

\section{THE INTERNET-ENABLED INTERVIEW}

\section{E-Mail Invitation}

The respondents were sent email invitations, which did not list the studies, but simply invited the respondent to participate. These respondents had previously agreed to participate in market research studies through a 'double opt-in' procedure, in which they agreed on two separate occasions to participate and not to be eliminated from e-mail invitations. 
Table 1. The 36 Elements and the Structure which Served as the Organizing Principle for the Database. A Similar General Structure of Four Silos and Nine Elements Per Silo was Used Across Studies

\author{
Silo 1 - Product Description \\ Filtered tap water... ALL OF THE GOOD, none of the bad \\ Pure, fresh spring water ... directly from the source \\ Clear, pure mineral water with just the right balance of minerals \\ Seltzer water with just the right tang at the end \\ Water cooler water...cold, clear and clean \\ Flavored water with bubbles dancing on your tongue \\ Spring water... available in the gallon size or in individual bottles \\ $24 \mathrm{oz}$. sport bottle of spring water for those that are always on the go \\ Bubbly water in a premium glass container... for the everyday or a high class affair \\ Silo B - Mood or Secondary Product Feature \\ When it's hot outside, water is very refreshing \\ Chilled... or with lots of ice cubes \\ Calcium and other minerals added for your health \\ Premium quality ... that great classic taste, like it used to be \\ You can just savor it when you think about it during work and school \\ $100 \%$ natural ... with new flavors every month to keep you tantalized \\ With a splash of lemon or lime for a little extra zing \\ You can imagine the taste as you walk in the door \\ So refreshing, you practically have to lick your lips twice after each sip \\ Silo 3 - Emotion, Situation \\ Quick and fun ... drinking alone doesn't have to be ordinary \\ When you think about it, you have to have it ... and after you have it, you can't stop drinking it \\ Fills that empty spot in you...just when you want it \\ When you're sad, it makes you glad \\ Now you can escape the routine ... a way to celebrate special occasions \\ A joy for your senses... seeing, tasting \\ An outrageous experience ... shared with family and friends \\ Pure ecstasy \\ It satisfies THE THIRST \\ Silo 4 - Brand or Reassurance \\ By Brita \\ From Poland Spring \\ From Dasani \\ From Aquafina \\ From Evian \\ From your local bottled water company \\ Poured fresh, especially for you ...by you \\ Simply the best water in the whole wide world \\ With the safety, care and cleanliness that makes you trust it \& love it all the more
}




\section{The 'Study Wall'}

When the respondent clicked on the link to participate in the general study (Crave It! or Drink It! or Healthy You!, respectively) he was automatically guided to a 'wall' Which presented the different available studies. The respondent could then choose a study in which they were interested in participating. Fig. (1) shows an example of the wall for the Drink It! studies. In order to ensure that all the studies would acquire a sufficient number of respondents, the wall was set up to be dynamic. That is, the study with the greatest number of respondents was located at the bottom right corner of the studies, whereas the study with the fewest number of respondents was located at the top left. This strategy helped to increase the number of respondents in the less popular studies. Furthermore, to ensure that a sufficient number of respondents participated in a study, the different studies were monitored and sometimes suspended, giving a chance for the less popular studies to be selected. Suspended studies whose quota was filled disappeared from the wall, forcing respondents to choose other studies. This strategy allowed the different studies to have at least 150 respondents each.

\section{THE SEQUENCE OF ACTIVITY IN THE INTER- VIEW}

All interviews for the water studies were conducted over the Internet, among U.S. respondents who agreed to participate. The interviews began with an orientation page, which described the study but did not give the respondent any hints about correct answers to the conjoint part of the study.

After the respondent read the orientation page, he was immediately presented with the first part of the interview, which comprised the 60 unique test concepts. The respondent rated the test concepts in his permutation set, one concept at a time, on an anchored 9-point rating scale. Only the end-points were anchored. The anchors changed depending upon the study. The nine point scale is easy to use and unambiguous once anchors are attached to the endpoints of the scales. After the respondent typed in his rating the computer program automatically advanced to the next concept, which was created in real time by reassembling the elements locally according to the respondents individualized experimental design.

Since the purposes of the three studies varied, the rating questions changed a bit from study to study. However, the general meaning of the scale is acceptance, from low to high, as follows:

1. Crave It! database: How intense is your CRAVING for this water?

$$
1=\text { not craveable at all ..... } 9=\text { very intense. }
$$

2. Drink It! database: How much do you want to drink this water?

$$
1=\text { not at all } \ldots \ldots \ldots \ldots \ldots . . .9=\text { very much. }
$$

3. Healthy You! database: How do you feel about this water?

$$
1=\text { hate it ................. } 9=\text { love it. }
$$

The final portion of the interview comprised the selfprofiling classification questionnaire, which allows the respondent to profile himself on a variety of questions, ranging from the standard geo-demographics (gender, age, market), to reasons for brand use, to state of thirst, medical condition, etc. The geo-demographics were the same across all three

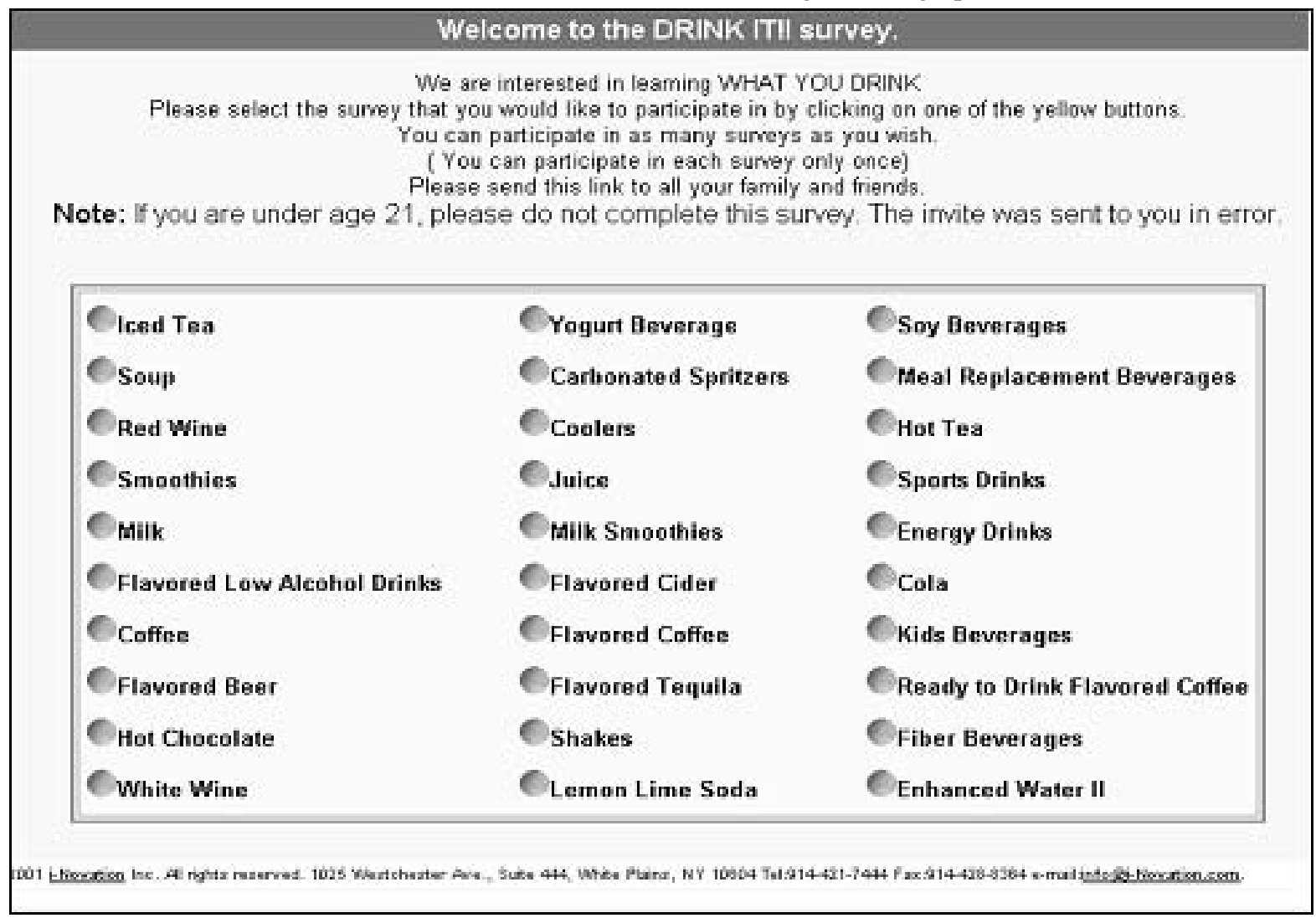

Fig. (1). The study wall for drink It! 
databases, but the other questions about attitudes towards brand and health differed, depending upon the specific database being created. Thus, the Crave It! questionnaire dealt with issues involving response to brands and products, times when the water was consumed, when craved, and other such product-related questions. The Drink It! classification was similar to the Crave It! questionnaire, but focused on the respondent behavior with respect to beverages rather than foods. In contrast, the Healthy You! classification questionnaire focused more on the respondent's health concerns.

The Internet-based interview took an average of 15 minutes. The 15 minute modal time was occasionally as short as 10 minutes or as long as 25 minutes. On average $50 \%$ of the respondents who began a study completed it, which represents a typical drop rate for these types of studies [12].

\section{DATA ANALYSIS}

Data analysis for conjoint studies involves a standard sequence of data transformation, followed by individual-level regression analysis and then by clustering to reveal groups of respondents with similar patterns of utilities. The experimental design is set up so that each of the 36 concept elements is statistically independent of every other element, a design structure which allows ordinary least squares regression (OLS) models to be fit to the individual respondent data.

Prior to the analysis the data was transformed at the individual respondent and concept level.

\section{Transform 1 (Persuasion Model)}

The objective here was to create a simple 0 to 100 scale, keeping the relative magnitudes of the ratings similar to the relative magnitudes on the original 9-point scale. The linear or affine transform was made so that a rating of 1 was transformed to 0 , a rating of 5 was transformed to 50, a rating of 9 was transformed to 100, and so forth. Transform 1 simply regenerated a new scale with no loss of information. The persuasion data from Transform 1 are used to develop concept-response segments, i.e., different groups of respondents showing similar mind-sets.

\section{Transform 2 (Interest Model)}

The objective here was to create a simple binary scale. Ratings of 1-6 were transformed to 0 to denote 'no interest' in the concept; ratings of 7-9 were transformed to 100 to denote 'interest' in the concept. Transform 2 follows the convention in consumer research to look at respondent data as indicating membership in a group - interested or not interested, with the analysis focused on the proportion of respondents interested in a concept.

The OLS model can be written very simply as follows:

$$
\underset{\mathrm{k}_{36}(\text { Element } 36)}{\text { Rating }}=\mathrm{k}_{0}+\mathrm{k}_{1}(\text { Element } 1)+\mathrm{k}_{2}(\text { Element } 2) \ldots
$$

The quantitative analyses for segmentation and consistency use the persuasion data (Transform 1). The substantive analysis about responses to the ideas contained within the concept element use the interest data (Transform 2). Except where noted below, the discussion will deal with the results from Transform 2.
A key benefit of the foregoing OLS model is its ability to identify the basic response to water through the additive constant, $\mathrm{k}_{0}$. The additive constant is the estimated interest or rating of the concept if no elements were present in the concept. Clearly, the additive constant is a theoretical and estimated one, emerging from the regression, since all tested concepts comprised a minimum of two elements and a maximum of four elements. The additive constant provides, however, a sense of the basic interest in the concept. Furthermore, by knowing the additive constant, and the magnitudes of the elements, it becomes possible to determine whether a high score for a concept results from the contribution of strong performing elements with a weak basic interest versus the contribution of weak performing elements with a strong basic interest, or something in-between. This fundamental knowledge generates insight into what makes a strong message - basic interest, powerful messaging, or a combination of the two.

The 36 individual-element utilities themselves are also important, for they show the contributory power of the different elements. Unlike conventional conjoint analysis methods that use 'effects-modeling' in ordinary regression, the current method uses true dummy variable modeling. The utilities in this current study can be compared across the four silos, and indeed across the different studies. There is no worry that the utilities must add to a constant, as there is with conventional conjoint analysis [20]. Thus, a +5 in one study has the same interpretation as a +5 in another study; there is no worry that the presence of other concept elements will distort the value of an element's utility.

The persuasion model has two major uses:

1. Goodness of Fit of the Equation to the Raw Data. OLS provides the researcher with a measure of respondent consistency. The $\mathrm{R}^{2}$ statistic (square of the multiple correlation) is generated on a respondent by respondent basis, and shows the proportion of variability in a respondent's ratings that can be traced to the presence/absence of the concept elements. The $\mathrm{R}^{2}$ statistic varies from a high of 1.00 meaning that the equation fits the respondent's data perfectly, down to a low of 0.00 meaning that the equation bears no relation to the data so the ratings are essentially random with respect to the elements. With 60 observations corresponding to the concepts, and 36 independent variables corresponding to the concept elements, the stage is set for a fair evaluation of the model at the individual respondent level. Fig. (2) shows the distribution of $\mathrm{R}^{2}$ values for the Drink It! data, and suggests that most of the individual respondents generated good, albeit not perfect, linear models. The $\mathrm{R}^{2}$ values are reasonably high at an individual level, suggesting respondent consistency. This consistency adds credibility to the data, and overcomes some of the objections by skeptics that unsupervised respondents in the internet-based interview will assign numbers at random. They do not.

2. Segmentation. The coefficients from the individual persuasion models are used to divide respondents by patterns. Segmentation will be discussed further on in this paper. 


\section{RESULTS AND DISCUSSION}

\section{Consistency of Data at the Individual Respondent Level}

The first analysis looks at the distribution of the goodness-of-fit statistic (multiple $\mathrm{R}^{2}$ ). Fig. (2) shows the results for the Drink It! study. Each circle corresponds to a respondent. The data suggest that respondents are consistent in their ratings, although as one might expect there are a number of respondents whose data suggest poor fit of their individual model. These inconsistent respondents generate data that might be dropped from the study, but as Moskowitz et al. [21] showed, dropping these inconsistent respondents will not change the general pattern of utilities. These inconsistent respondents merely add some noise to the overall results. It's worthwhile noting that this pattern of relatively high $\mathrm{R}^{2}$ statistics applies to the other databases as well. Perhaps the reason is that respondents disinterested in the study drop out before they complete the interview, leaving only those respondents who are interested to complete the interview.

\section{Measuring the Latent Interest in Water Versus Latent Interest in other Beverages}

This paper deals with the results from three databases. One database, Drink It!, suffices to show the nature of latent interest in water as a beverage. The more respondents who $\log$ into the study, the more we can conclude that 'water' as a beverage is interesting. The more respondents who complete the interview versus $\log$ in, the greater should be the topic. Fortunately for the Drink It! database, we have statistics for 30 beverages. The different beverages have been sorted by the percent of completes, defined as the ratio of completes to log-ins (see Table 2).

1. Log-ins. If a beverage is 'interesting' to respondents, then we expect to see a large number of log-ins. Sports beverages and meal replacement beverages show the highest number of log-ins. Yogurt beverages show the lowest number of log-ins. Flavored water is approximately in the middle, but fairly high, suggesting a great deal of latent interest in this beverage category.

2. Percent completes. If a beverage shows a high percentage of completes (i.e., completed interviews) relative to other beverages, then we can assume that the elements for this beverage are relatively more interesting than the other beverages, because the structure of the interview is the same. We see that flavored water, by itself, is one of the least interesting topics. About $46 \%$ of the respondents complete the interview. In contrast, $62 \%$ of the respondents complete the interview on hot tea. Thus, although a lot of respondents log-in, a great deal of them drop out, suggesting that they get bored during the course of the interview. Once a respondent participates in the interview, the topical content of the elements for flavored water simply does not hold the respondent's interest.

3. $\quad$ Percent female respondents. In these studies typically more women than men participate. The appropriate question is not the percent of female respondents, but whether water has a percent of respondents higher or lower than the median. Table $\mathbf{2}$ suggests that flavored water is about at the median with $75 \%$ of the respondents being women, so it is not of unusual interest to women as are juice spritzers (88\%) and coolers $(87 \%)$. In contrast, far more women are interested in participating in a study on flavored water than energy drinks $(46 \%)$ or sports drinks $(32 \%)$, which we could conclude to be masculine-oriented beverages.

\section{BASIC INTEREST IN WATER FROM THE DIFFER- ENT DATABASES (ADDITIVE CONSTANT)}

The key data from these water studies comes from the utilities, and the additive constant, which measures baseline interest in the product category without the benefit of

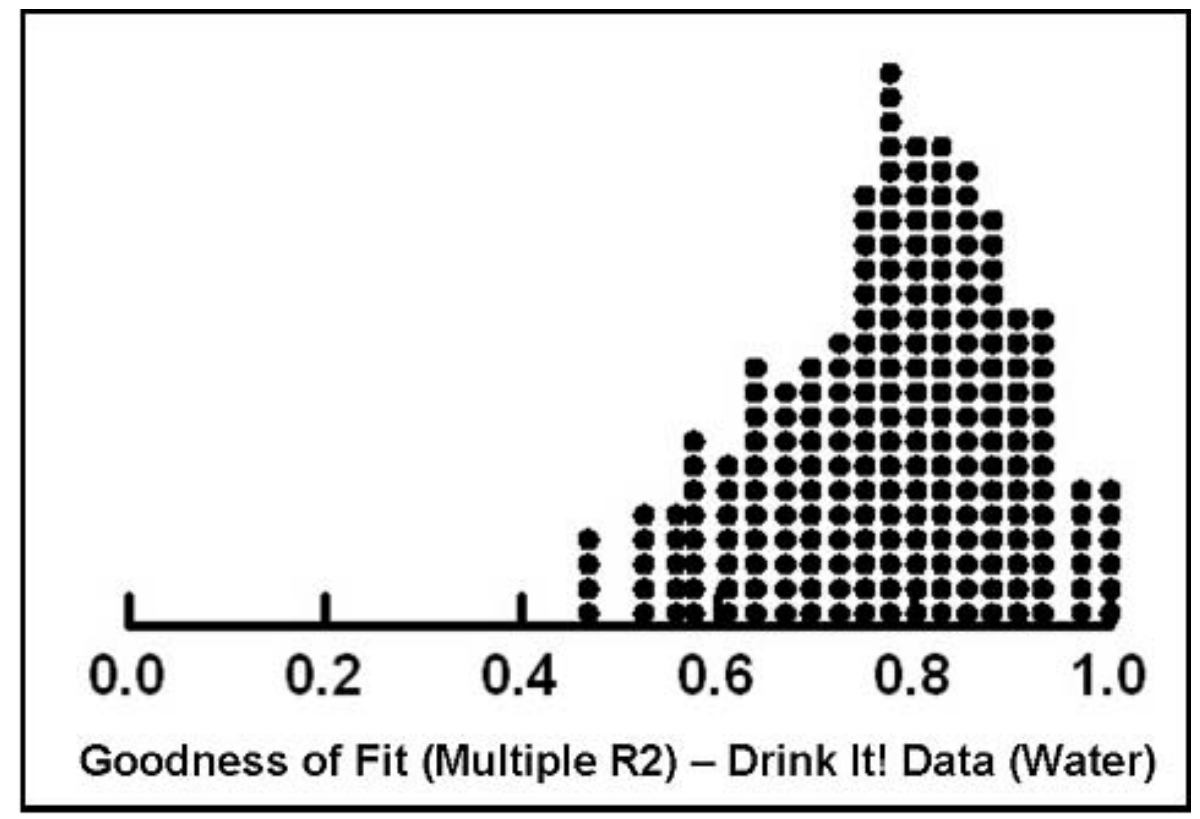

Fig. (2). Distribution of goodness of fit (R2 statistic for individual models, in the Drink It! database. Each circle corresponds to a respondent. The abscissa shows the fraction (i.e., percentage) of variability in the respondent's 9-point ratings that can be attributed to the concept elements. Any value for R2 exceeding 0.6 is highly significant, and suggests a consistent response pattern. 
Table 2. Pattern of Completes, Female Respondents, Total Completes and total Log-Ins in a Large Scale Data Base (Drink It! 2003)

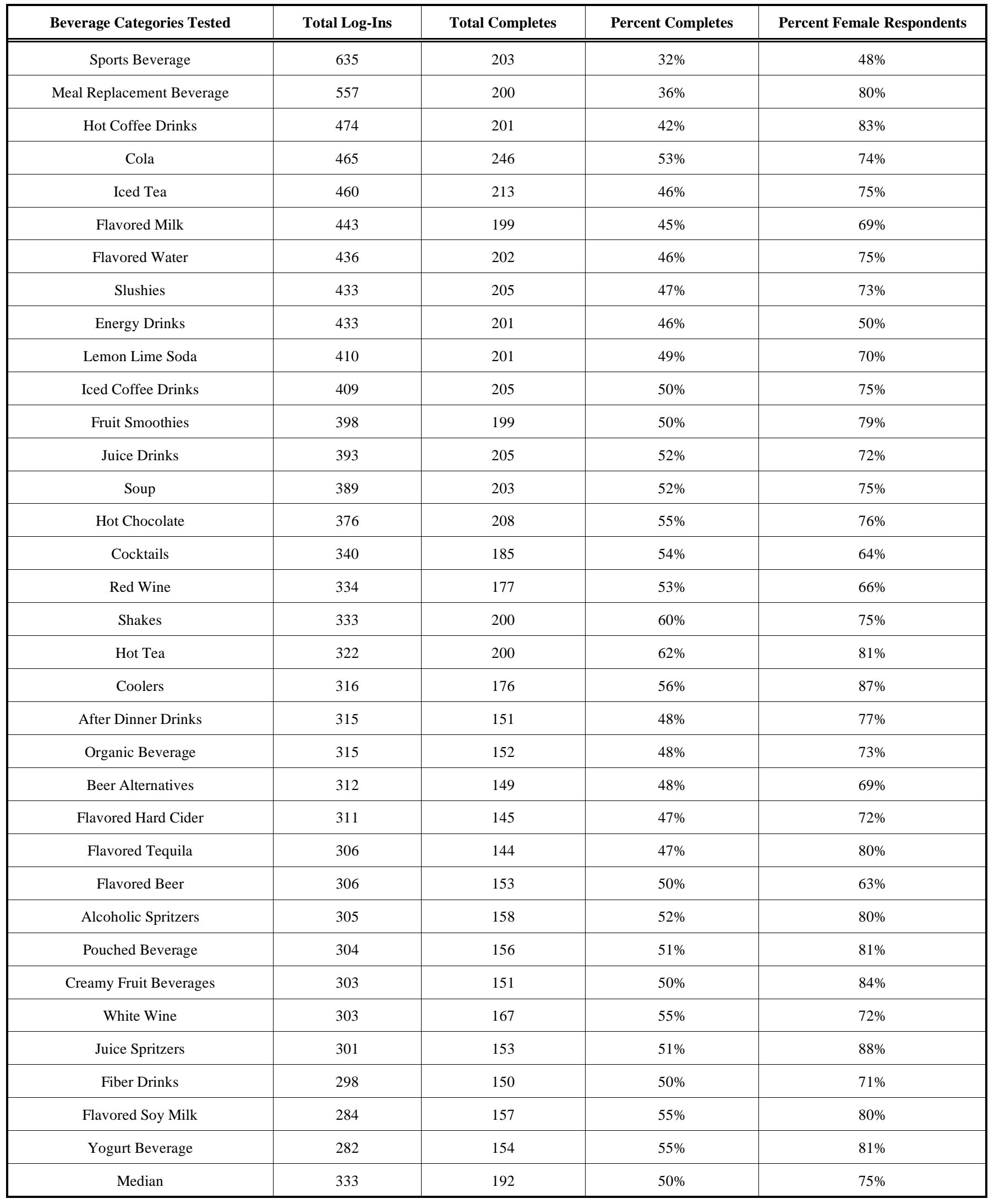


elements. Table 3 compares the additive constant for the different water studies. The basic interest for water is only modest, at least among adults. The additive constant from 2001 , for example, suggests that only $30 \%$ of the adult respondents would be interested in water. Moving up to 2002 and teens, we see that $42 \%$ of the respondents are interested when the product is positioned as 'healthful', but $50 \%$ are basically interested when the product is positioned as a beverage. Whether this increase in basic interest is due to an increasing interest in water or whether it is due to the rating question is not clear. We do see, however, that when the rating question is basic interest in a beverage (Drink It! 2002 and 2003, respectively) there is virtually no change in the basic $50 \%$ level of interest.

Table 3. Additive Constant for the Five Databases Dealing with Water

\begin{tabular}{|c|c|c|}
\hline Study & Group & Additive Constant \\
\hline \hline Crave It! 2001 & Adult & 30 \\
\hline Crave It! 2001 & Teen & 59 \\
\hline Healthy You! 2002 & Adult & 42 \\
\hline Drink It! 2002 & Adult & 50 \\
\hline Drink It! 2003 & Adult & 51 \\
\hline
\end{tabular}

\section{ADULTS SHOW A NARROW RANGE OF UTILITY VALUES ACROSS THE FOUR STUDIES}

A key benefit of the dummy variable regression model is the researcher's ability to interpret the utility value in terms of absolutes, relative to a meaningful zero. Thus, a utility of +5 means that $5 \%$ of the respondents would change their rating from disinterested to interested if the concept element were put into the concept. The utility value can be compared across studies, allowing us to merge all of the elements into a single table, sort the utilities, and then discover which elements remain consistently highly. We see this comparison in Table 4, where the elements are sorted from high to low, based on the utility values from the total panel. Table 4 shows only partial data.

Three clear findings emerge from looking at the elements that exhibit the highest and lowest achieved utilities.

1. Narrow range of utilities for the total panel. Across the four studies on water done with adults, which comprised 144 elements, selected to cover a range of features, emotions, health, brand, etc., only four elements achieved a total utility of 10 or higher. Similarly, only three elements achieved a -10 or lower.

2. Purity and cold perform best. The top three elements deal with cold, pure water (Pure, fresh spring water ... directly from the source; Water cooler water...cold, clear and clean; Chilled... or with lots of ice cubes). The fourth deals with flavors (Refreshing flavors such as lemon, berry, orange, or tropical), but the key word may be 'refreshing'.

3. Unusual or unexpected features do not delight. The bottom three elements, dealing with flavored water in an off-handed way, may have an 'added element' that just doesn't fit, such as 'tang at the end'.(Seltzer water ... with just the right tang at the end; Lightly flavored and sweetened plus a little caffeine for a revitalizing taste; Seltzer water with just the right tang at the end).

\section{Adults Versus Teens - Same or Different Patterns?}

The first It! database, created in 2001, comprised one set of studies for adults, one set for teens. The design and execution of the studies was the same, but the utility values radically differ by age. Table 4 shows partial data for the winning and losing elements.

1. The additive constant for adults is 30 , whereas the additive constant for teens is 59, virtually twice as high. We interpret this to mean that the basic interest (i.e., conditional probability) of a respondent saying 'I crave this water product' is virtually twice as high for teens as it is for adults. Only $30 \%$ of the adults would rate water from 7-9 on the 9-point scale, without any additional elements, whereas $59 \%$ of the teens would rate water from 7-9. This difference in age groups is highly significant.

2. The adults find three elements exceptionally interesting. These elements talk about pure, fresh and cold:

a. Pure, fresh spring water ... directly from the source (adults $=+12$ ).

b. Water cooler water...cold, clear and clean (adults $=+11)$.

c. Chilled... or with lots of ice cubes (adults $=+10$ ).

1. Teens show no strong performers. The best performers have low utilities. Two of them are the same as the two winning adult elements.

a. Pure, fresh spring water ... directly from the source (teens $=+6)$.

b. Water cooler water...cold, clear and clean (teens = $+5)$.

c. With a splash of lemon or lime for a little extra zing (teens $=+4)$.

1. Teens show a smaller range of utilities than do adults. The range for adults is a high of +12 and a low of -14 . The range for teens is a high of +6 and a low of -4 . This difference in range and in the additive constant is important. For teens a highly scoring concept will come about primarily through the contribution of a high additive constant (59). The elements themselves do not do much to contribute to the teen's response. For adults, however, it is the elements that must do the work.

2. Brand names did not add materially to concept acceptance, either among adults or among teens. It is the particular message, not the brand name, that does the work of convincing consumers. Brand names may be presumed to incorporate other benefits. However, when the brand name itself is used as a component of the concept, these other implicit benefits are not strong enough to drive up the utility of the brand name. 


\section{CONCEPT-RESPONSE SEGMENTATION AND THE EMERGENCE OF DIFFERENT MIND-SETS}

The relatively narrow range of utilities shown in the data from the total panel suggests one of two possibilities. The first possibility is that there are really no dramatic differences among the respondents in terms of their mind-sets. Elements neither dramatically attract nor repel the vast majority of respondents, save for a few positive ones (e.g., the statement 'pure fresh water...directly from the source, which scored a +12 among adult respondents in the Crave 2001 study).

A more plausible reason is that the total panel comprises groups of different mind-respondents, having the property that what one group likes but another group dislikes. One consequence of such countervailing forces, existing within the same data set, is that the utilities of the concept elements may average out to near 0 , despite the high level of liking by one group and the high level of disliking by another group.

The 36 utilities obtained from the 'persuasion' model of each respondent show in detail the pattern of likes and dislikes for that individual. This pattern of 36 numbers can be used to compare the different respondents, and divide them into two or more groups, such that the patterns of utilities within a group are similar, but the average patterns across the different groups differ.

The segments are defined by inter-stimulus distances, which are measured by the statistic (1-R). The value $R$ is defined as the Pearson correlation coefficient between two people based upon their 36 utilities. The additive constant is not considered in this analysis. The Pearson statistic varies from a low of -1 where two patterns are exactly opposite, through a middle level of 0 where two patterns are not related, to a high of +1 where two patterns can be superimposed and look exactly alike. The distance between respondents is the statistics 1-R, where $\mathrm{R}$ is the Pearson correlation. When $R=1$ (to items show same pattern), then their distance is $1-1$ or 0 . When $R$ is -1 , so the two patterns move in opposite directions, then $1-\mathrm{R}$ is $1--1$ or 2 .

An important outcome of segmentation is the emergence of new groups of respondents with different mind-sets. We can get a sense of the power of segmentation by comparing two scatter-plots, both from the Drink It! database (see Figs. 3 and 4). The first scatter-plot, Fig. (3), comes from the plot of the 36 utilities for four different age groups defined in the classification. Each point in the scatter-plot corresponds to a particular concept element. For the most part the scatter-plot suggests that what appeals to one age group will appeal to the other age groups. Fig. (4) shows what happens when we divide the population of respondents into four groups based upon the pattern of utilities, rather than upon the self-profiled geo-demographics. The patterns emerging from segmentation suggest greater segment-to-segment differences.

\section{Going More Deeply into Mind-Sets about Bottled Water}

Let us finish the empirical part of this paper with an analysis of the different mind-sets from three databases covering different topics (Crave It! 2001, Drink It! 2003, Healthy You! 2002). As noted above these three databases directed respondents to evaluate water according to different

Table 4. Winning and Losing Elements for Adults and Teens from the 2001 Crave It! Database

\begin{tabular}{|c|c|c|}
\hline Crave 2001 & Adults & Teens \\
\hline Additive Constant & 30 & 59 \\
\hline \multicolumn{3}{|l|}{ Winning Adult Elements } \\
\hline Pure, fresh spring water ... directly from the source & 12 & 6 \\
\hline Chilled... or with lots of ice cubes & 10 & 3 \\
\hline \multicolumn{3}{|l|}{ Losing Adult Elements } \\
\hline Now you can escape the routine ... a way to celebrate special occasions & -2 & 1 \\
\hline When you're sad, it makes you glad & -5 & -4 \\
\hline Water cooler water...cold, clear and clean & 11 & 5 \\
\hline With a splash of lemon or lime for a little extra zing & 3 & 4 \\
\hline \multicolumn{3}{|l|}{ Losing Teen Elements } \\
\hline You can imagine the taste as you walk in the door & 0 & -1 \\
\hline Calcium and other minerals added for your health & -2 & -1 \\
\hline When you're sad, it makes you glad & -5 & -4 \\
\hline
\end{tabular}




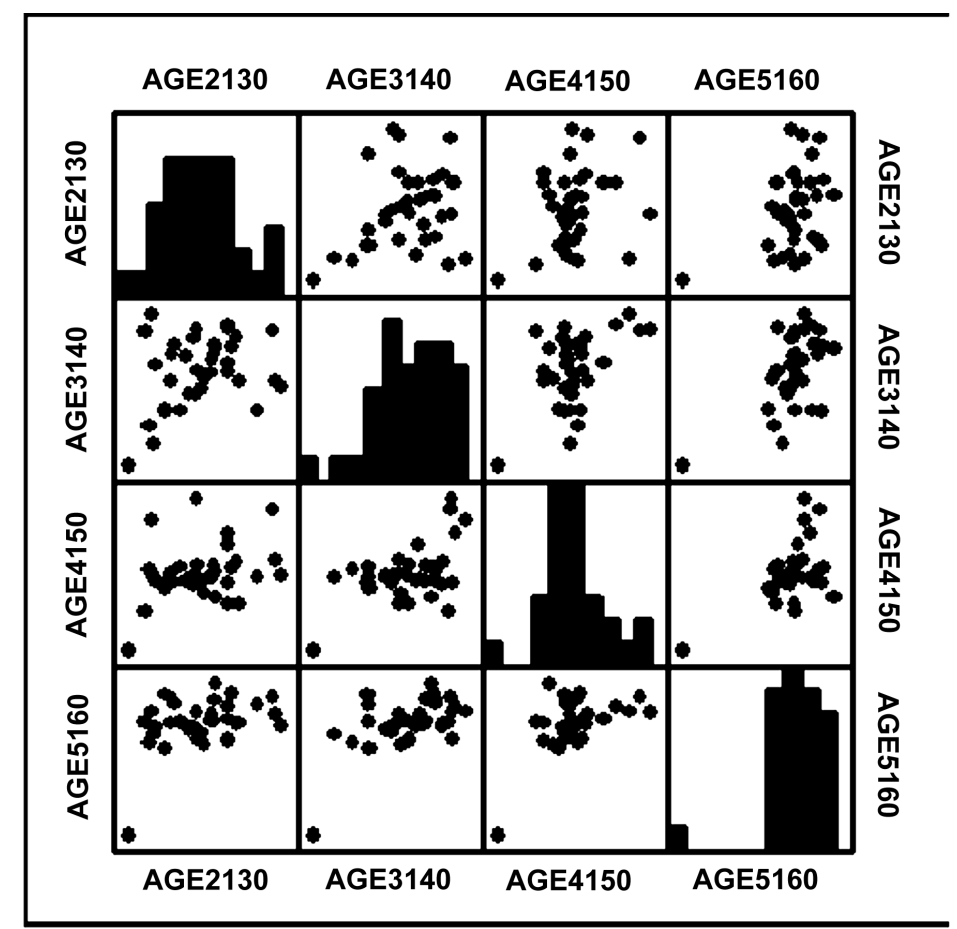

Fig. (3). Scatter-plot of 36 utilities from the Drink It! database, for four age groups. Each circle corresponds to a specific concept element. The histogram shows the distribution of utility value for a specific age subgroup.

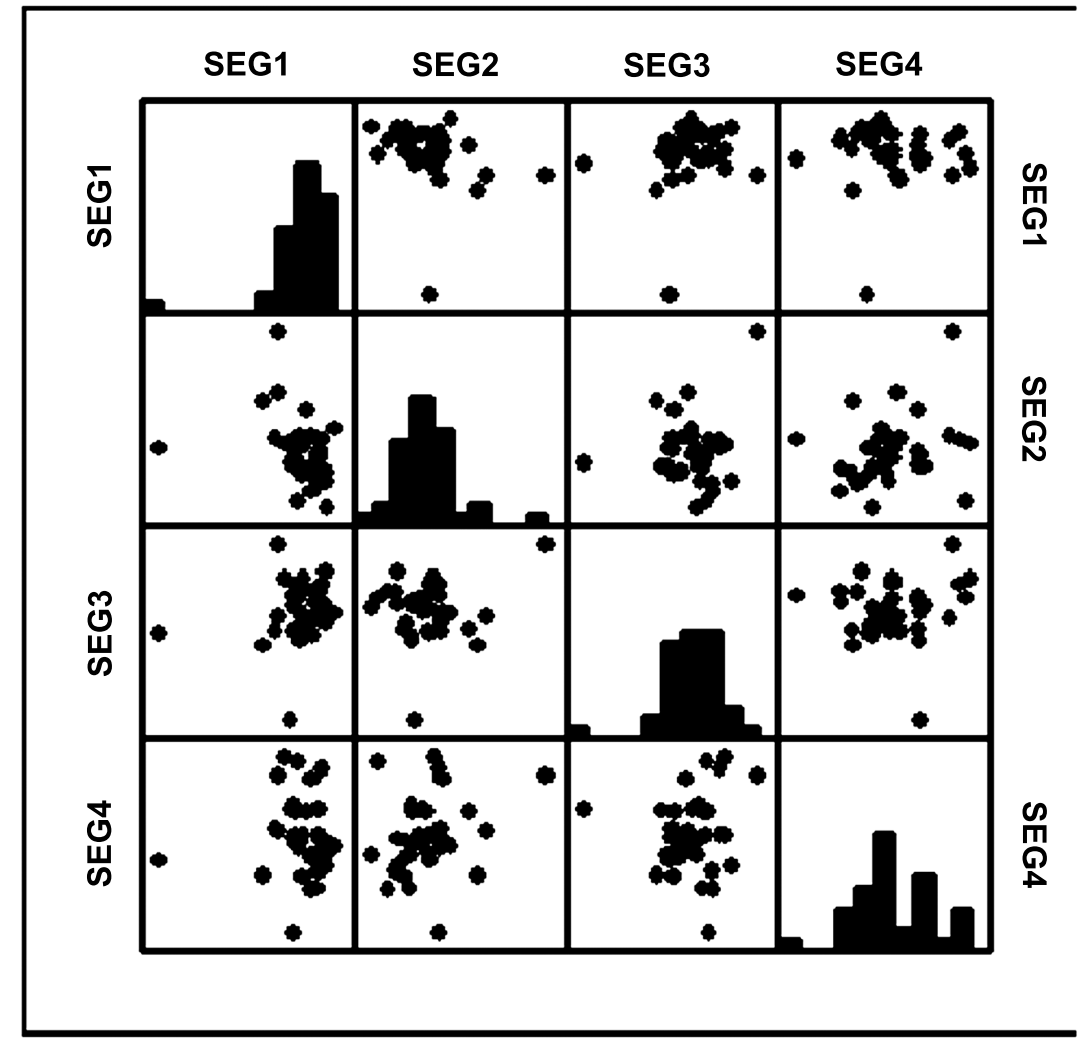

Fig. (4). Scatter-plot of 36 utilities from the Drink It! database, for the four segments developed using concept-response segmentation.

criteria. However, we might simplify the studies by assuming that each study asked for a rating of concept acceptance, albeit phrased in the appropriate fashion consistent with the objectives of the databases. The question is whether or not the different studies generate similar mind-sets.
Segmenting respondents into mind-sets, so-called latent segmentation, is not as straightforward as dividing respondents by objective criteria such as gender, age and income. Two complicating factors enter the scene. First, the segmentation method may influence the results. Fortunately the 
segmentation method was the same for all three databases estimation of persuasion utilities, the statistic (1-Pearson R) as the measure of distance between respondents, followed by k-means clustering [11]. Second, the number of segments to be extracted has to be both minimal for statistical robustness, and finally interpretable.

Rather than extracting the same number of segments for each of the three databases, we extracted the fewest number of segments that were interpretable for each study. Healthy You! generated two segments, Crave It! (adult) generated three segments, and Drink It! generated four segments. We looked for commonalities among the segments, to see whether the segmentation reappeared across databases. Three general 'super-segments' emerged, based upon similarities in the patterns of utilities and the type of elements that rose to the top in each segmentation. Table $\mathbf{5}$ shows this match-up.

\section{DISCUSSION AND CONCLUSIONS}

The discussion divides into two distinct sets of topics substantive issues about water, and methodological issues about creating a database about mind-sets using Internetbased research, conjoint analysis, and segmentation.

\section{SUBSTANTIVE ISSUES}

\section{Creating Archival Databases to Understand Product Categories}

The notion of an archival database for ideas is a continuing motive underlying this research. Although researchers are accustomed to databases for the performance of physical materials, and marketers are accustomed to databases for inmarket product performance (e.g., sales) there is really no database of ideas to which a product developer or a marketer can turn. With today's plethora of information the marketer can purchase reams of data about product sales, and can turn to specialists in so-called market mix analysis to identify what are the levers, i.e. the drivers of sales.

When it comes to ideas that work or don't work among consumers, however, there is no such repository, perhaps because ideation and innovative behaviors don't appear to go together with normative measuring. The business libraries are filled with books about how to come up with the perfect idea, how to jump the curve and be creative, innovative, and a whole host of other 'ives'. But, at the same time there is no lexicon or encyclopedia to turn to which will show how ideas work. This information is locked up in the head of the employees. When the knowledgeable employee leaves, dies, retires, or changes jobs within the company a lot of the information about 'what works' goes with them.

The databasing of ideas about water, shown for five total studies in this paper, constitutes a beginning in idea management. There are techniques and programs to measure ideas, but no easy to access technology that can work with the user's needs (e.g., find me a good vitamin for a water), and match that idea with a specific product, and with the user's reaction to that idea. This contribution is of importance to marketing and R\&D alike, who struggle with what works, what does not. With a limited amount of money it's probably better to buy this information off the shelf in a 'marketer's database' than to keep commissioning the same study, time after time.

\section{What Makes Winning Concept Elements and what Makes Poor Elements}

Concept performance in this study has been reported in terms of utility values from the interest model. Looking at the different tables showing utility values, and at Table 6 which shows the performance of all the products, one might well ask about the characteristics that make a good concept element. Is it the idea of the element, or the expression of the idea, or both? Certainly it is not length - both short phrases and long phrases do well, and do poorly. It's also not brand name, nor is it short 'fluff' phrases. Nor is it long, health statements that go into detail about the product, at least not to the general population. Rather, it looks as if those elements that talk about 'good and natural' water, that paint a word picture of purity, that don't try to be cute, that don't communicate esoterics, do well.

Table 5. Match Up of Segments to Create Super-Segments

\begin{tabular}{|c|c|c|c|}
\hline \multicolumn{4}{|c|}{ Super-Segment \#1 - ' Want Refreshment' } \\
\hline Drink It! & Segment 1 & Icy cold water & 80 of $216(38 \%)$ \\
\hline Healthy You! & Segment 1 & Refreshing & 130 of $245(53 \%)$ \\
\hline \multicolumn{4}{|c|}{ Super-Segment \#2 -' Want Flavor' } \\
\hline Drink It! & Segment 2 & Replace carbonated beverages & 35 of $216(16 \%)$ \\
\hline Drink It! & Segment 3 & Flavor \& refreshment seekers & 28 of $216(13 \%)$ \\
\hline \multicolumn{4}{|c|}{ Super-Segment \#3 - ' Want Functionality' } \\
\hline Crave It! & Segment 3 & Water /Thirst Reducer, Sipping & 64 of $199(32 \%)$ \\
\hline
\end{tabular}


Table 6. Interest Utilities for Adults from the Four Data Bases Dealing with Bottled Water

C2001 = Crave It! (run in 2001), H2002 = Healthy You! (run in 2002)

D2002 = Drink It! (run in 2002), D2003 = Drink It! (run in 2003)

\begin{tabular}{|c|c|c|c|}
\hline Database & Silo & Element & Utility \\
\hline & & Strong Performing Elements & \\
\hline $\mathrm{C} 2001$ & A & Water cooler water...cold, clear and clean & 11 \\
\hline $\mathrm{C} 2001$ & $\mathrm{~B}$ & Chilled... or with lots of ice cubes & 10 \\
\hline D2002 & A & Pure, fresh spring water ... directly from the source & 8 \\
\hline D2003 & A & Flavored water made from pure, fresh spring water ... directly from the source & 8 \\
\hline $\mathrm{H} 2002$ & A & Pure, fresh taste & 8 \\
\hline $\mathrm{H} 2002$ & A & Natural spring water with purity guaranteed & 8 \\
\hline D2002 & A & Spring water ... contains the antioxidants your body needs & 6 \\
\hline D2003 & A & Flavored spring water $\ldots$ with the antioxidants your body needs & 6 \\
\hline $\mathrm{H} 2002$ & A & All natural...no artificial flavors, colors or sweeteners & 6 \\
\hline D2002 & A & Enhanced water that contains ingredients to energize you ... specially formulated to keep you going. & 6 \\
\hline D2003 & $\mathrm{B}$ & $100 \%$ natural & 6 \\
\hline D2003 & A & Highly purified water with delicious flavors & 5 \\
\hline C2001 & A & Spring water... available in the gallon size or in individual bottles & 5 \\
\hline $\mathrm{C} 2001$ & $\mathrm{~B}$ & When it's hot outside, water is very refreshing & 5 \\
\hline $\mathrm{H} 2002$ & A & A healthy beverage that tastes great & 4 \\
\hline D2003 & A & Lightly sweetened with natural fruit flavors & 4 \\
\hline $\mathrm{H} 2002$ & A & Spring water, deliciously flavored naturally, with a hint of fruit & 4 \\
\hline $\mathrm{H} 2002$ & A & Crisp and refreshing & 4 \\
\hline D2002 & A & With a total of 9 essential vitamins and minerals & 4 \\
\hline $\mathrm{C} 2001$ & $\mathrm{~B}$ & Premium quality ... that great classic taste, like it used to be & 4 \\
\hline D2002 & $\mathrm{B}$ & $100 \%$ natural & 4 \\
\hline C2001 & $\mathrm{C}$ & When you think about it, you have to have it ... and after you have it, you can't stop drinking it & 4 \\
\hline $\mathrm{H} 2002$ & $\mathrm{C}$ & A water you feel good about giving your family & 4 \\
\hline $\mathrm{C} 2001$ & $\mathrm{C}$ & It satisfies THE THIRST & 4 \\
\hline $\mathrm{H} 2002$ & $\mathrm{C}$ & May reduce your risk of high blood pressure and stroke & 4 \\
\hline $\mathrm{C} 2001$ & $\mathrm{D}$ & From Evian & 4 \\
\hline
\end{tabular}




\begin{tabular}{|c|c|c|c|}
\hline Database & Silo & Element & Utility \\
\hline & & Elements that are Probably Irrelevant & \\
\hline D2003 & A & Cools you down & 3 \\
\hline D2003 & $\mathrm{B}$ & Drinking flavored water is cool and inviting & 3 \\
\hline D2002 & $\mathrm{B}$ & With Calcium for strong bones and teeth & 3 \\
\hline $\mathrm{H} 2002$ & $\mathrm{~B}$ & Full of antioxidants and phytonutrients that help you maintain a healthy heart & 3 \\
\hline D2002 & $\mathrm{B}$ & So refreshing you want to savor how it makes you feel & 3 \\
\hline $\mathrm{C} 2001$ & $\mathrm{~B}$ & With a splash of lemon or lime for a little extra zing & 3 \\
\hline $\mathrm{C} 2001$ & $\mathrm{D}$ & From Aquafina & 3 \\
\hline D2003 & $\mathrm{D}$ & Keeps your body hydrated & 3 \\
\hline $\mathrm{H} 2002$ & $\mathrm{D}$ & Endorsed by the American Heart Association & 3 \\
\hline D2003 & $\mathrm{D}$ & Multi serve containers ... so you always have enough! & 3 \\
\hline $\mathrm{C} 2001$ & $\mathrm{D}$ & Poured fresh, especially for you ...by you & 3 \\
\hline $\mathrm{H} 2002$ & $\mathrm{D}$ & Endorsed by the American Dietetic Association & 3 \\
\hline $\mathrm{C} 2001$ & $\mathrm{D}$ & With the safety, care and cleanliness that makes you trust it $\&$ love it all the more & 3 \\
\hline D2002 & A & Highly purified water & 2 \\
\hline D2002 & $\mathrm{B}$ & So refreshing ... you have to drink another & 2 \\
\hline $\mathrm{H} 2002$ & $\mathrm{~B}$ & $\begin{array}{l}\text { An essential source of the nutrients that are important for heart health ... like potassium, magnesium, } \\
\text { and folic acid }\end{array}$ & 2 \\
\hline H2002 & $\mathrm{C}$ & So quick and easy & 2 \\
\hline D2002 & $\mathrm{C}$ & When you think about it, you have to have it ... and after you have it, you can't stop drinking it & 2 \\
\hline D2003 & $\mathrm{C}$ & Enhanced water that contains ingredients to energize you ... & 2 \\
\hline $\mathrm{C} 2001$ & $\mathrm{C}$ & Fills that empty spot in you...just when you want it & 2 \\
\hline D2002 & $\mathrm{C}$ & Simply the best & 2 \\
\hline D2003 & $\mathrm{C}$ & Simply the best & 2 \\
\hline $\mathrm{H} 2002$ & $\mathrm{C}$ & Fills that empty spot in you...just when you want it & 2 \\
\hline $\mathrm{H} 2002$ & $\mathrm{C}$ & Such pleasure ... knowing you're drinking something healthy & 2 \\
\hline $\mathrm{H} 2002$ & $\mathrm{C}$ & Calms you down...just what you need when you're feeling stressed & 2 \\
\hline D2003 & $\mathrm{C}$ & Looks great, smells great, tastes delicious & 2 \\
\hline $\mathrm{C} 2001$ & $\mathrm{C}$ & Pure ecstasy & 2 \\
\hline D2002 & $\mathrm{C}$ & Oh so Refreshing! & 2 \\
\hline $\mathrm{H} 2002$ & $\mathrm{C}$ & As part of a low fat, low cholesterol diet, may reduce the risk of some forms of cancer & 2 \\
\hline D2002 & $\mathrm{C}$ & It quenches THE THIRST & 2 \\
\hline
\end{tabular}


(Table 6). Contd.....

\begin{tabular}{|c|c|c|c|}
\hline Database & Silo & Element & Utility \\
\hline $\mathrm{C} 2001$ & $\mathrm{D}$ & From Dasani & 2 \\
\hline D2002 & $\mathrm{D}$ & Keeps your body hydrated & 2 \\
\hline H2002 & $\mathrm{D}$ & From VitaminWater & 2 \\
\hline D2002 & $\mathrm{D}$ & Low calorie alternative to sugar ladened soft drinks & 2 \\
\hline H2002 & $\mathrm{D}$ & Endorsed by the American Diabetes Association & 2 \\
\hline D2002 & $\mathrm{D}$ & With the safety, care and quality that makes you trust it all the more & 2 \\
\hline H2002 & $\mathrm{D}$ & Recommended by nutritionists and dietitians & 2 \\
\hline $\mathrm{H} 2002$ & A & $100 \%$ organic & 1 \\
\hline D2002 & B & Drinking enhanced water is so inviting & 1 \\
\hline $\mathrm{H} 2002$ & $\mathrm{~B}$ & Provides essential minerals for bone health, including calcium, phosphorous, and magnesium & 1 \\
\hline D2003 & B & Low in calories & 1 \\
\hline D2003 & $\mathrm{B}$ & Premium quality & 1 \\
\hline D2003 & B & With natural botanicals & 1 \\
\hline $\mathrm{H} 2002$ & B & With lutein, an antioxidant that may play a role in maintaining good vision & 1 \\
\hline D2003 & $\mathrm{B}$ & So refreshing ... you have to drink some more & 1 \\
\hline D2002 & $\mathrm{C}$ & Quick and fun ... water is no longer boring! & 1 \\
\hline D2002 & $\mathrm{C}$ & Relaxes you after a busy day & 1 \\
\hline D2003 & $\mathrm{C}$ & Take a break from your busy day & 1 \\
\hline C2001 & $\mathrm{C}$ & A joy for your senses... seeing, tasting & 1 \\
\hline $\mathrm{H} 2002$ & $\mathrm{C}$ & Even better for you than you thought & 1 \\
\hline C2001 & $\mathrm{C}$ & An outrageous experience ... shared with family and friends & 1 \\
\hline D2002 & $\mathrm{D}$ & Multi serve containers ... so you always have enough! & 1 \\
\hline D2003 & $\mathrm{D}$ & With the safety, care and quality that makes you trust it all the more & 1 \\
\hline C2001 & A & Filtered tap water ... ALL OF THE GOOD, none of the bad & 0 \\
\hline D2002 & A & Made with mineral water ... to deliver great taste & 0 \\
\hline D2003 & A & Refreshing flavors in a rainbow of colors & 0 \\
\hline $\mathrm{C} 2001$ & B & $100 \%$ natural ... with new flavors every month to keep you tantalized & 0 \\
\hline C2001 & B & You can imagine the taste as you walk in the door & 0 \\
\hline D2002 & $\mathrm{B}$ & You can imagine the taste even before you drink it & 0 \\
\hline D2003 & $\mathrm{C}$ & Quick and fun ... water is no longer boring! & 0 \\
\hline D2002 & $\mathrm{C}$ & Looks great, smells great, tastes delicious & 0 \\
\hline D2002 & $\mathrm{C}$ & A wonderful experience ... shared with family and friends & 0 \\
\hline D2003 & $\mathrm{C}$ & Pure satisfaction & 0 \\
\hline $\mathrm{H} 2002$ & $\mathrm{D}$ & From Poland Spring & 0 \\
\hline D2002 & $\mathrm{D}$ & From Evian & 0 \\
\hline D2003 & $\mathrm{D}$ & A great tasting alternative to sport drinks & 0 \\
\hline H2002 & $\mathrm{D}$ & Recommended by your doctor & 0 \\
\hline D2002 & A & Water fresh from the source with fluoride ... cold, clear and clean & -1 \\
\hline D2003 & A & Flavored water with a splash of fizz & -1 \\
\hline $\mathrm{H} 2002$ & B & $\begin{array}{l}\text { A good source of fiber, important in reducing your risk of chronic diseases like heart disease and } \\
\text { diabetes }\end{array}$ & -1 \\
\hline C2001 & B & You can just savor it when you think about it during work and school & -1 \\
\hline H2002 & B & Contains the essential nutrient choline ... shown to improve memory and learning & -1 \\
\hline
\end{tabular}




\begin{tabular}{|c|c|c|c|}
\hline Database & Silo & Element & Utility \\
\hline $\mathrm{C} 2001$ & $\mathrm{C}$ & Quick and fun ... drinking alone doesn't have to be ordinary & -1 \\
\hline H2002 & $\mathrm{C}$ & Promotes digestion & -1 \\
\hline D2002 & $\mathrm{D}$ & From Aquafina & -1 \\
\hline $\mathrm{C} 2001$ & $\mathrm{~B}$ & Calcium and other minerals added for your health & -2 \\
\hline D2003 & $\mathrm{C}$ & Relaxes you after a busy day & -2 \\
\hline C2001 & $\mathrm{C}$ & Now you can escape the routine ... a way to celebrate special occasions & -2 \\
\hline D2002 & $\mathrm{C}$ & Now you can escape the routine ... a way to celebrate special occasions & -2 \\
\hline D2002 & $\mathrm{D}$ & From Poland Spring & -3 \\
\hline \multirow[t]{2}{*}{ D2003 } & $\mathrm{D}$ & From Glaceau & -3 \\
\hline & & Elements that Detract from Interest & \\
\hline H2002 & A & Sparkling water with just the right amount of effervescence & -4 \\
\hline D2003 & B & Designed especially for active women with isoflavones, and a separate one for men & -4 \\
\hline D2003 & B & Made with organic flavors & -4 \\
\hline $\mathrm{C} 2001$ & $\mathrm{C}$ & When you're sad, it makes you glad & -5 \\
\hline C2001 & A & Flavored water with bubbles dancing on your tongue & -7 \\
\hline C2001 & A & Seltzer water with just the right tang at the end & -14 \\
\hline
\end{tabular}

What are these ideas? For the most part they're simple, and not with too much flavor connotation, although if the flavor is mentioned it probably should be simply stated, and without much affectation. Here are elements that do quite well, with basic utility values of 10 or higher, a level that has been found to co-vary with good market performance:

Pure, fresh spring water ... directly from the source

Water cooler water...cold, clear and clean

Chilled... or with lots of ice cubes

Refreshing flavors such as lemon, berry, orange, or tropical

All of these phrases paint simple word pictures of water. Even the flavor statement is fairly simple.

Let's contrast this with those phrases that do quite poorly

Seltzer water ... with just the right tang at the end

Lightly flavored and sweetened plus a little caffeine for a revitalizing taste

Seltzer water with just the right tang at the end
These poorer performers do not talk health, but rather about some level of artificiality (e.g., the tang at the end or the caffeine in the water). It appears, therefore, that the secret to a good concept element for the total panel is to paint this word picture of simple and pure, in short words. Consumers respond negatively if the concept of water is conjoined with something that doesn't really belong to it.

\section{Reliability of Element Utilities Across Databases}

One of the interesting outcomes of this study is the relative stability of common concept elements across time and databases. The databases were originally created in order to understand the consumer mind-set with regard to foods (Crave It!), beverages (Drink It!) and health-oriented foods/beverages (Healthy You!). Although the basic design of the databases was similar (four silos, nine elements per silo) only in some cases were the elements identical in two or more databases.

By looking at the utilities for the same elements across databases and thus, years, it becomes possible to assess the reliability of the conjoint method used here. One should keep in mind that each respondent in a study evaluated a unique 
Table 7. How Elements Appearing in Two or More Databases Perform in Each Database

\begin{tabular}{|c|c|c|c|c|}
\hline Database & Pair & & Element & Utility \\
\hline $\mathrm{C} 2001$ & A & E02 & Pure, fresh spring water $\ldots$ directly from the source & 12 \\
\hline D2003 & B & E35 & Resealable single serve container ... to take with you on the go & 7 \\
\hline D2002 & $\mathrm{B}$ & E35 & Resealable single serve container ... to take with you on the go & 5 \\
\hline D2003 & $\mathrm{D}$ & E15 & $100 \%$ natural & 6 \\
\hline D2002 & $\mathrm{D}$ & E15 & $100 \%$ natural & 4 \\
\hline D2003 & $\mathrm{E}$ & E11 & With Calcium for strong bones and teeth & 5 \\
\hline D2002 & $\mathrm{E}$ & E12 & With Calcium for strong bones and teeth & 3 \\
\hline H2002 & G & E29 & From Aquafina & 5 \\
\hline D2003 & G & E29 & From Aquafina & 3 \\
\hline $\mathrm{C} 2001$ & G & E31 & From Aquafina & 3 \\
\hline D2002 & G & E29 & From Aquafina & -1 \\
\hline $\mathrm{H} 2002$ & $\mathrm{H}$ & E30 & From Dasani & 3 \\
\hline $\mathrm{C} 2001$ & $\mathrm{H}$ & E30 & From Dasani & 2 \\
\hline D2003 & $\mathrm{I}$ & E31 & Keeps your body hydrated & 3 \\
\hline D2002 & $\mathrm{I}$ & E31 & Keeps your body hydrated & 2 \\
\hline $\mathrm{C} 2001$ & $\mathrm{~J}$ & E21 & Fills that empty spot in you...just when you want it & 2 \\
\hline D2003 & $\mathrm{M}$ & E21 & Simply the best & 2 \\
\hline D2002 & $\mathrm{M}$ & E21 & Simply the best & 2 \\
\hline D2002 & $\mathrm{O}$ & E36 & With the safety, care and quality that makes you trust it all the more & 2 \\
\hline D2003 & $\mathrm{O}$ & E36 & With the safety, care and quality that makes you trust it all the more & 1 \\
\hline D2003 & $\mathrm{P}$ & E24 & Looks great, smells great, tastes delicious & 2 \\
\hline D2002 & $\mathrm{P}$ & E24 & Looks great, smells great, tastes delicious & 0 \\
\hline D2002 & $\mathrm{Q}$ & E19 & Quick and fun ... water is no longer boring! & 1 \\
\hline D2003 & $\mathrm{Q}$ & E19 & Quick and fun ... water is no longer boring! & 0 \\
\hline $\mathrm{C} 2001$ & $\mathrm{R}$ & E29 & From Poland Spring & 2 \\
\hline $\mathrm{H} 2002$ & $\mathrm{R}$ & E28 & From Poland Spring & 0 \\
\hline D2002 & $\mathrm{R}$ & E28 & From Poland Spring & -3 \\
\hline $\mathrm{C} 2001$ & $\mathrm{~S}$ & E23 & Now you can escape the routine $\ldots$ a way to celebrate special occasions & -2 \\
\hline D2002 & $\mathrm{S}$ & E23 & Now you can escape the routine ... a way to celebrate special occasions & -2 \\
\hline D2002 & $\mathrm{T}$ & E13 & $\begin{array}{l}\text { Bubbly water in a premium glass container ... for both the everyday and the more special occa- } \\
\text { sion }\end{array}$ & -3 \\
\hline $\mathrm{C} 2001$ & $\mathrm{~T}$ & E09 & Bubbly water in a premium glass container... for the everyday or a high class affair & -9 \\
\hline D2002 & $\mathrm{U}$ & E04 & Seltzer water ... with just the right tang at the end & -12 \\
\hline $\mathrm{C} 2001$ & $\mathrm{U}$ & E04 & Seltzer water with just the right tang at the end & -14 \\
\hline
\end{tabular}


set of combinations, rating 36 elements in 60 combinations. This type of evaluation constitutes a 'torture' test for the elements.

Table 7 shows that for the most part the utilities are highly reproducible across studies. That is, the difference between the utilities of the same element in two or more databases tend to be about 3.0 or less.

Given the different years, contexts, nature of elements, always-varying backgrounds, and the range of the utilities in the entire study, it appears that that the conjoint method used for these studies, IdeaMap.Net ${ }^{\circledR}$ generates utilities that are both remarkably reliable and quite discriminating.

\section{METHODOLOGICAL ISSUES}

A key issue in the consumer research world revolves around the use of research procedures that have become overly complex. The methodological issues below are based upon a view that easier research is eventually more powerful research, and that the results should be clear, reliable, valid, and actionable.

\section{Statistical Modeling - Trading off Between Full Concepts and Dummy Variable Modeling}

A close look at today's consumer research methods published in archival journals (e.g., Journal of Marketing Research) reveals a plethora of methods for running conjoint analysis studies. Over the past forty years, conjoint analysis, basically a study of the response to mixtures, has evolved from pair-wise trade-offs of components [16] to experimental designs, whether complete or fractional factorial, and encompassing different points of view. One of these viewpoints is that respondents cannot really understand what a concept means unless the respondent is presented with all of the components of a concept. It is difficult for the respondent to impute missing information in a concept. A diametrically opposite viewpoint is that the respondents have little trouble evaluating incomplete information because that is what they do everyday in their worlds. Few consumers pay deep attention to the stimuli around them when they shop, especially to food and beverages which, as a result, are called lowinvolvement. Certainly, there are those who read every label, watch the nutritional composition of what they eat, and otherwise pay close attention. These individuals are probably in the small minority.

Given the researcher's proclivity to test complete concepts, with all of the silos being present, how then does the researcher analyze the data? If a concept contains one element, and only one element from every silo then, perforce, the data are collinear. That is, if there are $\mathrm{M}$ elements in a silo, then knowing the condition of M-1 elements (all elements but one) automatically tells the researcher and the regression program the state of the $\mathrm{M}^{\text {th }}$ element. Trying to run a dummy variable regression on the data, after it has been coded to 1 (element present) or 0 (element absent), will generate an error message. The regression will not run.

The present study, like others run by the authors uses a different experimental design where there are a limited number of silos in each concept (2-4), and each silo has a valid 'zero condition'. Thus, the concepts are, by their very nature, incomplete. In such situations the modeling using ordinary least squares is straightforward, except for the need to avoid problems where all the ratings are the same. This problem can be handled by adding a small random number $\left(<10^{-4}\right)$ to every rating, so that the regression always runs.

\section{THE VALUE OF CONCEPT-RESPONSE SEGMEN- TATION}

Segmentation studies have two major benefits - scientific and application.

\section{Science}

Researchers want to understand the reason behind individual differences. The variability from person to person can be taken as an annoying fact of life, or it can be treated as an aspect of nature to be investigated. For instance, individual differences in the acceptance of different types of sensory signals (e.g., sweetness) mean that the population does not all like the same product. Studies of population variability and rules for such variability are perfectly valid findings for a scientific career. However, for practical application, there must be more, such as organizing rules that predict the nature of this variation in the same way that genomics seeks to understand the 'laws' of individual variation by understanding the rules of gene expression.

\section{Application}

Knowledge about individual variation has a dual aspect, which is far more practical, far more applied. Segmentation provides the marketer and researcher with an organizing principle for individual differences. To the degree that the marketer understands the nature of the different types of consumers in the marketplace, it will be possible to satisfy a range of tastes in an efficient manner. Knowing, for instance, that there are the different types of preference patterns for bottled water may help the marketer to develop a reasonable expectation on the number of satisfied consumers for any single marketing or development effort.

Bringing this point of view about segmentation closer to the topic of bottled water, we can see that there is room in the bottled water category for multiple products to live together. What one person dislikes intensely may not be an indication of poor product performance as much as an indication that the person falls into a specific mind-set segment.

\section{HOW INTERNET-RESEARCH CAN CHANGE THE BASE OF KNOWLEDGE}

When Internet-based research became popular about a decade ago, the initial questions dealt with the validity of the research. In the late 1990's the Internet promised to provide a lower cost venue in which to conduct the research. Those who had studied the history of research will recognize the Internet as yet another venue to acquire knowledge, beginning with person-to-person (via door-to-door), followed by the telephone, and mail, and now the Internet.

The key benefit of the Internet is ease of doing research. This ease translates into faster research, simpler to execute research, easier set up and take down, and more error free fielding. It is impossible to get into the consumer's mind in research, at least in quantitative research of this type, but it is now possible to do more powerful, self-correcting research, that contains in-born checks to guard against fraud, con- 
sumer disinterest, and phony data. The approach presented here, which uses experimental design, permutations of the design, and measures of consistency, represents one of those new methods of Internet-research whose power has been enhanced by the new technology. The ability to acquire masses of data easily, to model the data to the individual level, and to compare the utilities for like items across different element sets make this type of Internet research a very promising system for knowledge development.

\section{ACKNOWLEDGMENTS}

The authors would like to thank It! Ventures LLC for making the It! data available for Crave It! ${ }^{\mathrm{TM}}$, Healthy You! ${ }^{\mathrm{TM}}$, and both Drink It! ${ }^{\mathrm{TM}}$ databases. Dr. Howard Moskowitz wishes to thank his editorial assistant, Linda Lieberman, for editing his manuscripts and preparing them for production.

\section{REFERENCES}

[1] Sloan AE. What, when, and where Americans eat. Food Technol 2003; 57(8): 48-66.

[2] Organic Food Report. Natural, organic and functional beverages. Nutr Bus J 2000; 5(9): 1: 3-5.

[3] Flores L, Maier AS, Moskowitz HR. Accelerating development by understanding weak signals and strong communications: The case of bottled water: Unpublished manuscript 2005.

[4] Diehl JM, Bloh E. Altersunterschiede im Konsum alkoholfreier Getränke. Aktuelle Ernährungsmedizin 1985(10): 160-71.

[5] Elmadfa I, Huhn W, Eds. Consumption and preference of drinking water. In: Diehl JM, Leitzmann C, Eds. Measurement and determinants of food habits and food preferences. Wageningen, The Netherlands: Wageningen University 1985: 129-35.

[6] Holm L, Kildevang H. Consumers' views on food quality: A qualitative interview study. Appetite 1996; 27: 1-14.

[7] Mallevialle J, Suffet IH. Identification and Treatment of Tastes and Odors in Drinking Water. Denver, CO: American Water Works Association 1987.
[8] Moskowitz HR, Porretta S, Silcher, M. Concept Research in Food Product Design and Development. Ames, Iowa: Blackwell Professional 2005

[9] Herstatt C, von Hippel E. From experience: Developing new product concepts via the lead user method: A case study in a "Low Tech" field. J Prod Innov Manage 1992; (9): 213-21.

[10] Malefyt T. Ethnography and focus groups: Mutually exclusive? Brandweek (Lett) 2003; XLIV(43): 14.

[11] Systat, The System for Statistics Users manual. Chicago, ILL: Systat Software Inc. 1997.

[12] Beckley J, Moskowitz HR. Databasing the consumer mind: The Crave It! ${ }^{\mathrm{TM}}$, Drink It! ${ }^{\mathrm{TM}}$, Buy It! ${ }^{\mathrm{TM}} \&$ Healthy You! ${ }^{\mathrm{TM}}$ databases. Paper presented at the Institute of Food Technologists Annual Meeting, Anaheim, CA 2002.

[13] Moskowitz HR, German B, Saguy IS. Unveiling health attitudes and creating good-for-you foods: The genomics metaphor \& consumer innovative web-based technologies. CRC Crit Rev Nutr Food Sci 2005; 45: 165-91.

[14] McCutcheon A, Hagenaars J, Eds. Advances in Latent Class Modeling. Cambridge University Press: New York 1999.

[15] Moskowitz HR. Segmenting consumers world-wide: An application of multiple media conjoint methods. Proceedings of the $49^{\text {th }}$ ESOMAR Congress: Istanbul, Turkey 1996; 535-552.

[16] Johnson RM. Trade-off analysis of consumer values. J Market Res 1974; 11(S): 121-36.

[17] Cattin P, Wittink, DR. Commercial use of conjoint analysis: A survey. J Market 1982; 46: 44-53.

[18] Wittink DR, Cattin P. Commercial use of conjoint analysis: An update. J Market 1989; 53: 91-6.

[19] Moskowitz HR, Gofman A. System and method for performing conjoint analysis. US $200460538787,2004$.

[20] Box GEP, Hunter J, Hunter S. Statistics For Experimenters. New York: John Wiley 1978.

[21] Moskowitz HR, Gofman A, Itty B, Katz R, Manchaiah M, Ma Z Rapid, inexpensive, actionable concept generation and optimization - the use and promise of self-authoring conjoint analysis for the foodservice industry. Food Service Technol 2001; 1: 149-68.

Received: November 07, 2008

Revised: November 24, 2008

Accepted: November 25, 2008

(C) Maier et al.; Licensee Bentham Open.

This is an open access article licensed under the terms of the Creative Commons Attribution Non-Commercial License (http://creativecommons.org/licenses/by-nc/3.0/) which permits unrestricted, non-commercial use, distribution and reproduction in any medium, provided the work is properly cited. 